\title{
Research into polymer injection timing for Bohai heavy oil reservoirs
}

\author{
Lei-Ting Shi $\cdot$ Shi-Jie Zhu $\cdot$ Jian Zhang $\cdot$ \\ Song-Xia Wang $\cdot$ Xin-Sheng Xue $\cdot$ Wei Zhou \\ Zhong-Bin Ye
}

Received: 28 November 2013/Published online: 17 January 2015

(c) The Author(s) 2015. This article is published with open access at Springerlink.com

\begin{abstract}
Polymer flooding has been proven to effectively improve oil recovery in the Bohai Oil Field. However, due to high oil viscosity and significant formation heterogeneity, it is necessary to further improve the displacement effectiveness of polymer flooding in heavy oil reservoirs in the service life of offshore platforms. In this paper, the effects of the water/oil mobility ratio in heavy oil reservoirs and the dimensionless oil productivity index on polymer flooding effectiveness were studied utilizing relative permeability curves. The results showed that when the water saturation was less than the value, where the water/oil mobility ratio was equal to 1 , polymer flooding could effectively control the increase of fractional water flow, which meant that the upper limit of water/oil ratio suitable for polymer flooding should be the value when the water/oil mobility ratio was equal to 1 . Mean while, by injecting a certain volume of water to create water channels in the reservoir, the polymer flooding would be the most effective in improving sweep efficiency, and lower the fractional flow of water to the value corresponding to
\end{abstract}

L.-T. Shi $(\bowtie) \cdot$ J. Zhang $\cdot$ X.-S. Xue $\cdot$ W. Zhou

State Key Laboratory of Offshore Oil Exploitation,

Beijing 100027, China

e-mail: flygoslt@126.com

L.-T. Shi - S.-J. Zhu - Z.-B. Ye

State Key Laboratory of Oil and Gas Reservoir Geology

and Exploitation, Southwest Petroleum University,

Chengdu 610500, Sichuan, China

S.-X. Wang

Research Institute of Exploration and Development,

PetroChina Southwest Oil \& Gas Field Company,

Chengdu 610041, Sichuan, China

Edited by Yan-Hua Sun
$\Delta J_{\max }$. Considering the service life of the platform and the polymer mobility control capacity, the best polymer injection timing for heavy oil reservoirs was optimized. It has been tested for reservoirs with crude oil viscosity of 123 and $70 \mathrm{mPa} \mathrm{s}$, the optimum polymer flooding effectiveness could be obtained when the polymer floods were initiated at the time when the fractional flow of water were $10 \%$ and $25 \%$, respectively. The injection timing range for polymer flooding was also theoretically analyzed for the Bohai Oil Field utilizing relative permeability curves, which provided methods for improving polymer flooding effectiveness.

Keywords Heavy oil reservoir - Mobility ratio . Polymer injection timing - Injection timing range . Timing optimization

\section{Introduction}

Heavy oils account for about 69 percent of the total of about $17.8 \times 10^{8} \mathrm{~m}^{3}$ original oil in place discovered in offshore reservoirs in the Bohai Oil Field. For water flooding in heavy oil reservoirs, the swept volume by water during a pilot flood turns out to be very limited due to an excessively high water/oil mobility ratio and serious fingering. The average oil recovery of the overall development program is 20.2 percent in the Bohai Oil Field (Zhou 2009). Therefore, specific measures should be taken for most conventional heavy oil reservoirs to improve oil displacement efficiency during different oil production stages (Levitt et al. 2013). As for the Bohai Oil Field even if the oil recovery is improved by only $1 \%$, it will in effect result in obtaining the equivalent of another major oil field of hundreds of millions of tonnes without any exploration 
and development investment. Among different EOR techniques, polymer flooding, as a relatively mature technique (Chang 2011; Abu-shiekah et al. 2012; Delamaide et al. 2013), has been proven to be very effective in increasing oil recovery and decreasing water cuts in different scales of on-site polymer flood pilots conducted in the Bohai Oil Field (Ye et al. 2010; Zhang et al. 2011a, b; Kang and Zhang 2013; Shi et al. 2013).

In the course of water flooding in conventional heavy oil reservoirs, with an increase in water saturation, the water/oil mobility ratio will increase as well, resulting in a much higher increase in the water cut in heavy oil reservoirs than in light oil reservoirs (Kumar et al. 2005; Asghari and Nakutnyy 2008; Aktas et al. 2008; Mogbo 2011; Morelato et al. 2011; Liu et al. 2012). Influenced by such factors as reservoir heterogeneity, the polymer flood was initiated when the water cut of the produced fluids reached $60 \%$ for the SZ36-1 oil field, and the oil recovery factor increased by only 5-7 \% due to polymer floods (Zhang et al. 2007, 2009, 2013; Jiang et al. 2010; Kang et al. 2011), which was lower than that in the onshore light crude reservoirs (Asghari and Nakutnyy 2008). Meanwhile, the largest difference between onshore and offshore oil production is that the design service life of an offshore platform is less than 30 years (Rivas and Gathier 2013). Therefore, it is extremely important for offshore oil fields to select an optimum injection timing to initiate polymer floods in heavy oil reservoirs (Zhang et al. 2013) for better ultimate oil recovery.

Field tests show that the earlier the polymer flooding is performed, the better the water/oil mobility control is maintained with polymer solutions. This means that the injection timing of polymer solutions has a significant influence on the ultimate recovery factor (Ma 1995; Hu 2004; Alzayer and Sohrabi 2013). Therefore, appropriate polymer injection timing would helpful to effectively enhance oil recovery, lower the risks in polymer flooding in heavy oil reservoirs, and displace more oil during the service life of offshore platforms. In this paper, the effect of the water/oil mobility ratio on the efficiency of polymer flooding is studied at different fractional flows of water in heavy oil reservoirs using relative permeability curves, and then the polymer injection timing is optimized.

\section{Experimental}

\subsection{Materials}

Hydrophobically associating polyacrylamide (HAP2010, industrial purity) was commercially available, with a relative molecular weight of $1.0 \times 10^{7}$, degree of hydrolysis of 20 percent, and a hydrophobic group content of 1.0 percent. Injection water used in all tests had a total salinity of
$9,047 \mathrm{mg} / \mathrm{L}$, in which the mass concentrations of $\mathrm{Na}^{+} / \mathrm{K}^{+}$, $\mathrm{Ca}^{2+}, \mathrm{Mg}^{2+}, \mathrm{SO}_{4}^{2-}, \mathrm{HCO}_{3}^{-}$, and $\mathrm{Cl}^{-}$were 2,552, 569, 229, 37, 191, and 5,471 mg/L, respectively. The types of oils used, namely oil A and B, were the mixtures of diesel and dehydrated crude from the Bohai Oil Field, with viscosities of 70 and $123 \mathrm{mPa}$ s, respectively, at $65^{\circ} \mathrm{C}$. The oil viscosity was measured with a DV-IIIBrook-field viscometer.

\subsection{Experimental procedures and data processing method}

Natural cores were taken from the Bohai oil reservoirs, with a dimension of $2.5 \mathrm{~cm}$ in diameter and $7 \mathrm{~cm}$ in length. These cores had a gas permeability of about 2,000 $\times 10^{-3} \mu^{2}$ and porosity of about $30 \%$.

Water-oil/polymer solution-oil relative permeability curves were measured by an unsteady state method according to oil and natural gas industrial specifications SY/T 5435-2007, P.R. China. The experimental procedures are as follows (Crotti and Rosbaco 1988; Bakhitov et al. 1980): (a) The core was cleaned with solvent and dried with hot nitrogen and then evacuated; (b) Permeability was measured with gas; (c) The core was saturated with injection water, then the core porosity and permeability to water were calculated; (d) Oil was injected into the core at a rate of $0.1 \mathrm{~mL} / \mathrm{min}$ up to $3 \mathrm{PV}$ (pore volume) in order to reach the irreducible water saturation. Oil was injected into the core by an ISCO Model 260D pump; (e) The oil permeability was measured at irreducible water saturation; (f) The injection water was injected into the core at a rate of $1 \mathrm{~mL} / \mathrm{min}$ up to $10 \mathrm{PV}$ in order to reach the irreducible oil saturation; (g) The water permeability was measured at residual oil saturation; (h) The core was cleaned with solvent and dried with hot nitrogen and evacuated. Then steps from $b$ to e were repeated; (i) The polymer solution (polymer concentration was $1,750 \mathrm{mg} / \mathrm{L}$ ) was injected into the core at a rate of $1 \mathrm{~mL} / \mathrm{min}$ up to $10 \mathrm{PV}$ in order to reach the residual oil saturation; and (j) The permeability to polymer solution was measured at irreducible oil saturation. The volumes of oil and water produced were measured dynamically.

The water saturation at different periods was calculated by the material balance method, and the modified " $\mathrm{J} \cdot \mathrm{B} \cdot \mathrm{N}$ " method (Dou et al. 2007; Shi et al. 2001; Zhou et al. 2010; Delgado et al. 2013) was used to calculate the water-oil/ polymer solution-oil relative permeability. The effective viscosity $\mu_{\text {eff }}$ of the polymer solution was calculated with Eq. (1).

$\mu_{\mathrm{eff}}=\frac{R F}{R R F} \mu_{\mathrm{w}}$,

where $R F$ is the resistance factor, dimensionless; $R R F$ is the residual resistance factor, dimensionless; and $\mu_{\mathrm{w}}$ is the viscosity of water solution, $\mathrm{mPa}$ s. 


\section{Results and discussion}

\subsection{Relative permeability curves during water flooding} and polymer flooding

In experiments, the viscosity of the injection water and the polymer solution was 0.60 and $1.05 \mathrm{mPa}$ s, respectively, at $65{ }^{\circ} \mathrm{C}$. The relative permeability of the displaced and displacing phases (oil and water during water flooding, oil and polymer solution during polymer flooding) was measured, and the relative permeability curves are shown in Fig. 1.

In Fig. $1, K_{\mathrm{ro}}$ and $K_{\mathrm{rw}}$ are the oil and water relative permeability, respectively, during water flooding; and $K_{\text {rpo }}$ and $K_{\mathrm{rp}}$ are the oil and polymer solution relative permeability, respectively, during flooding; $S_{\mathrm{w}}$ is the water saturation.

With an increase in oil viscosity, the residual oil saturation increased in the relative permeability curves, which demonstrated that the performance of the displacing phase dropped (Jiang et al. 2008). Under the same water saturation, the relative permeability of cores to the polymer phase was far lower than that to the water phase, while the relative permeability of cores to the oil phase changed slightly; and the residual oil saturation decreased in the relative permeability curve during polymer flooding. This showed that polymer flooding could control the water/oil mobility and improve the oil displacement efficiency for heavy oil reservoirs (Shi et al. 2010).

\subsection{Effect of the fractional flow of water on injection timing of polymer floods}

According to the relative permeability curves during water flooding and polymer flooding, the mobility ratio $(M)$, the fractional flow of water $\left(f_{\mathrm{w}}\right)$, and the rate of increase of fractional water flow with water saturation $\left(\mathrm{d} f_{\mathrm{w}} / \mathrm{d} S_{\mathrm{w}}\right)$ could be obtained in the fractional flow equation

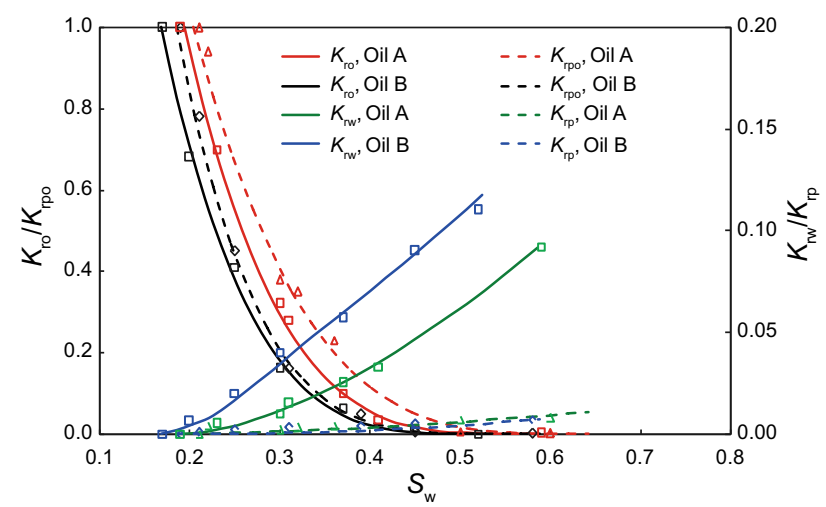

Fig. 1 Relative permeability curves during water flooding and polymer flooding
(Romero-Zeron et al. 2009; Torabi et al. 2013). During water flooding, the curves of the mobility ratio versus water saturation are shown in Fig. 2, and the fractional water flow curves and the rate of increase in the fractional water flow with water saturation are demonstrated in Fig. 3

Figure 2 indicates that at a water saturation of 0.35 , the water/oil mobility ratio is typically very unfavorable for oil $\mathrm{B}$; and a similar tendency is present for oil A when the water saturation is about 0.38 . During polymer flooding, the polymer solution/oil mobility ratio would be reduced to just slightly above 1.0. The injection of polymer solutions may increase the viscosity of the water phase and decrease the water mobility, indicating that improved sweep efficiency can be expected from polymer flooding.

As shown in Fig. 3, when the oil viscosity was relatively high, the fractional flow of water increased rapidly and reached its maximum levels at low water saturations. As a result, water channels may be formed in a short time due to serious viscous fingering, causing early water breakthrough and poor oil displacement efficiency.

The water/oil mobility ratio and the fractional flow of water increased quickly when the water saturation $\left(S_{\mathrm{w}}\right)$ increased. Therefore, oil recovery can be improved by injecting polymer solutions before the rate of increase of fractional water flow reached its maximum level. This was helpful to control mobility for stabilizing the water front, improve sweep efficiency and to increase displacement efficiency.

For oil B and A, when the water saturation was 0.186 and 0.252 , respectively, the rate of increase of fractional water flow reached its maximum, as soon as the water/oil mobility ratio was higher than 1 . The mobility ratio would increase dramatically when the water saturation was higher than 0.186 and 0.252 . At high mobility ratios viscous fingering occurred, leading to a poor sweep efficiency (Shi et al. 2012). A frontal-advance velocity cutoff would be established for mobility control with polymer floods

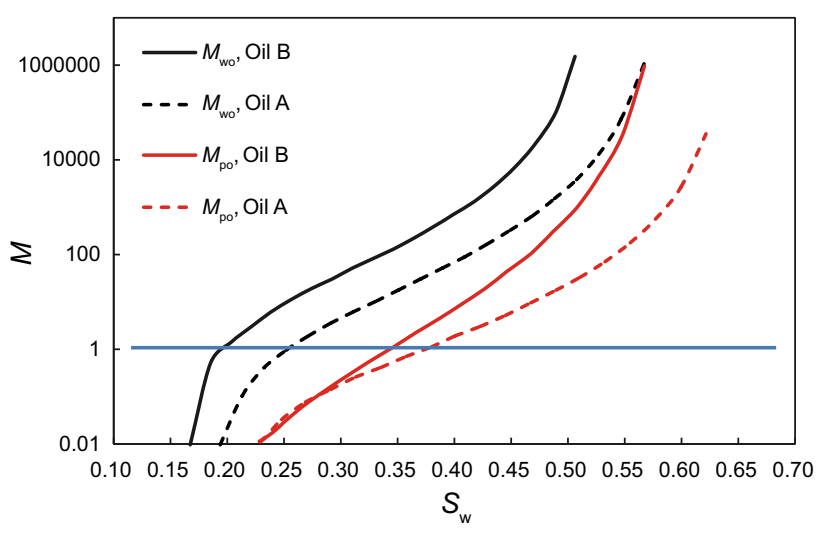

Fig. 2 Mobility ratios for crude oils of different viscosity 


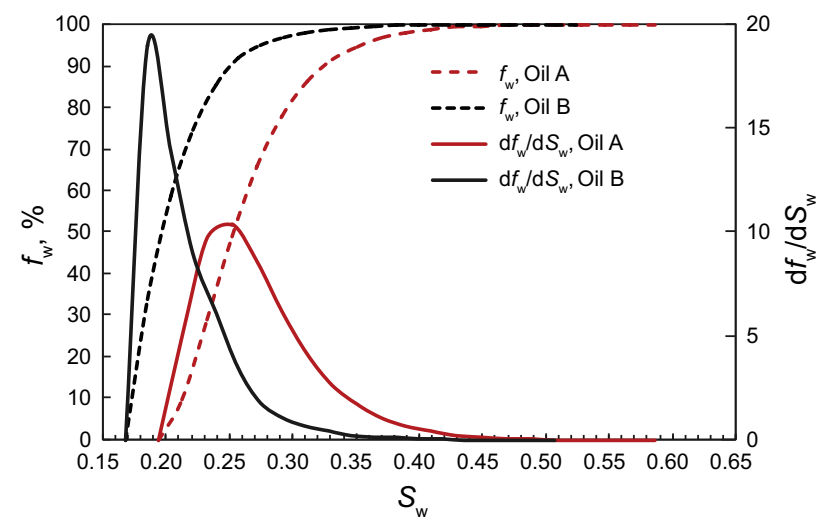

Fig. 3 The curves of fractional water flow and the rate of increase of fractional water flow

(Lee 2010), but the mobility control of polymer solution could become limited when the mobility ratio was too high during water flooding, leading to a poor polymer flood sweep efficiency in high viscosity reservoirs.

It was favorable to perform polymer flooding at relatively low water/oil mobility ratio when the polymer solution had enough ability to control flow mobility. Injection of polymer solutions would decrease the rate of increase of fractional water flow and extended the stable production period, so good displacing efficiency would be achieved. The upper water saturation limit of polymer flooding should be the saturation $\left(S_{\mathrm{wu}}\right)$ when the rate of increase of fractional water flow reached its maximum level. When $S_{\mathrm{w}} \leq S_{\mathrm{wu}}$, the ability of polymer floods to control flow mobility ratio has appeared to be affected significantly by the water saturation in the heavy oil reservoirs. While $S_{\mathrm{w}}>S_{\mathrm{wu}}$, polymer floods could not control flow mobility, finally resulting in poor displacement efficiency.

Thus, it was favorable to perform polymer floods before the rate of increase of fractional water flow reached its maximum level. The suitable water saturation for polymer floods should be less than 0.186 and 0.252 , respectively, for oil B and A. The water saturation was 0.186 and 0.252 , the rates of increase of fractional water flow was $34 \%$ and $50 \%$, respectively.

\subsection{Effect of dimensionless productivity index on injection timing of polymer floods}

The objective of mobility control is to improve the volumetric sweep efficiency of polymer floods. The oilfield responses are observed through an increase in injection pressure and reduced water cut (Mahani et al. 2011). The polymer solution slug would improve the volumetric sweep efficiency, resulting in a decrease in water cut; on the other hand, the polymer solution slug would lower the water injection capacity and the liquid producing capacity. The reduction of the liquid producing capacity generally took place in the initial stage of the polymer flooding process, and decreased slowly thereafter.

Figure 4 indicates that the water saturation of oil reservoirs increased during polymer flooding when the fractional flow of water was the same. Figure 5 shows that the dimensionless productivity index in the polymer flooding process was less than that in the water flooding process.

The difference between the dimensionless productivity indexes in the water flooding and polymer flooding processes are defined as follows:

$\Delta J=J_{\text {orw }}-J_{\text {orp }}$,

where $J_{\text {orw }}$ is the dimensionless productivity index in the water flooding process; $J_{\text {orp }}$ is the dimensionless productivity index in the polymer flooding process.

Figure 5 shows that $\Delta J$ increased at first and then decreased as the water saturation increased. The water/oil mobility ratio was low when the water saturation was relatively low. The water front was relatively stable, injection water could connect the flow channels in oil reservoirs, and thus $J_{\text {orw }}$ was relatively high. If the polymer solution was injected at this moment, the polymer mobility should be less than the oil mobility, resulting in an excessive pressure increase and lowering the dimensionless productivity index. This showed that the flow channels for initial water were connected together in oil reservoirs when the water saturation was relatively low. $\Delta J$ reached its maximum level $\left(\Delta J_{\max }\right)$ as the water saturation increased, which indicated that flow channels were formed in oil reservoirs due to water injection and the oil was displaced by injection water. After that, the injection water would preferentially flow through the high permeability channels, the fractional flow of water increased rapidly, water breakthrough was very fast and the volumetric sweep efficiency was low, so it was desirable to inject polymer solution to control the flow resistance in flow channels, which ultimately enhanced the displacement efficiency.

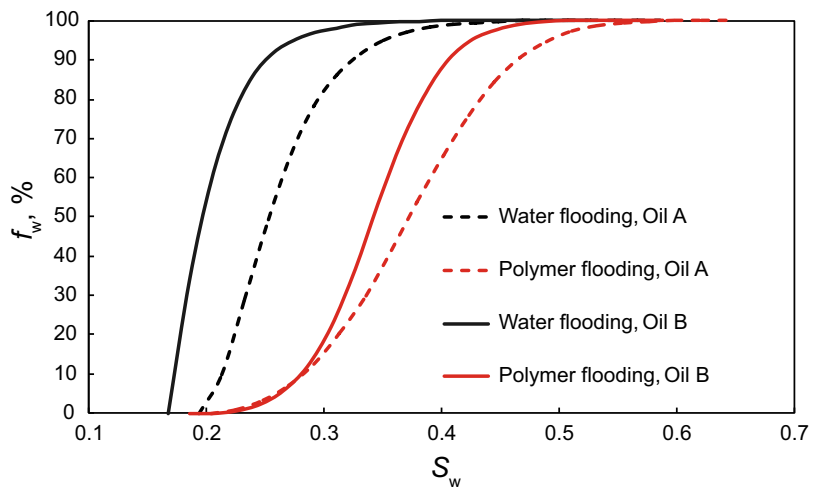

Fig. 4 The fractional water flow curves 


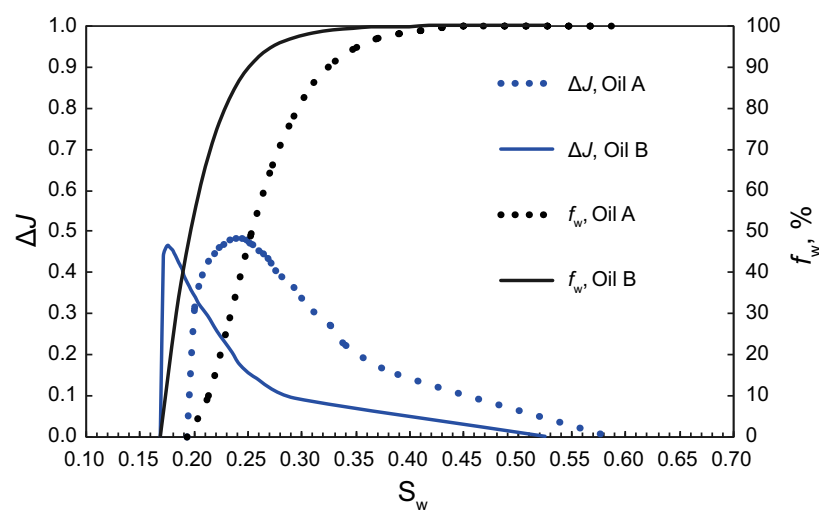

Fig. 5 Dimensionless productivity index during water flooding and polymer flooding

When $S_{\mathrm{w}} \leq S_{\mathrm{wL}}$ (where $S_{\mathrm{wL}}$ is the water saturation when $\Delta J$ reached its maximum level), the displacement effect of the polymer flood was similar to water flood. The main function of polymer floods was to form flow channels. The displacement efficiency of polymer floods would be below the desired level if the polymer solution was only used to build up flow channels. $S_{\mathrm{wL}}$ should be the water saturation lower limit for polymer floods. A certain amount of water is recommended to be injected into heavy oil reservoirs to create or connect flow channels before polymer flooding. Then the polymer solution is injected to modify the oil/water mobility, improve the volumetric sweep efficiency, and to enhance success rate of polymer floods. Therefore, when $\Delta J$ reaches maximum $\left(\Delta J_{\max }\right)$, the corresponding water saturation should be the lower limit of injection timing, which is also the start for polymer slug injection in heavy oil reservoirs.

When $S_{\mathrm{w}} \geq S_{\mathrm{wL}}$, the injection of a polymer solution slug would improve the volumetric sweep efficiency and oil recovery. For oil B and A, the corresponding suitable water saturation should be higher than 0.179 and 0.240 , respectively, for polymer flooding. When the water saturations were 0.179 and 0.240 , the rates of increase of fractional water flow were $10 \%$ and $25 \%$, respectively.

By analyzing the displacement mechanism of water flooding and polymer flooding, the injection timing for heavy oil B was in the range of 10-34\% of the fractional flow of water; and the injection timing for oil A was in the range of $25-50 \%$ of the fractional flow of water. During the service life of the offshore platform, the optimum injection timing for polymer flooding should be selected as $S_{\mathrm{wL}}$ in order to maximize the improvement of the oil recovery for the Bohai heavy oil reservoirs. Normally, under consideration of the mobility control ability of polymer solution, the higher the crude oil viscosity is, the earlier the polymer flooding injection timing should be. It could be realized that the polymer injection timing should be a little later if the ability of the polymer solution to control flow mobility is high enough, which also could achieve good displacement efficiency.

\section{Conclusions}

(1) For polymer solutions of the same mobility control ability, the polymer flood may be injected at relatively low water saturation to stabilize the water front and decrease the water cut when the oil viscosity is higher.

(2) The injection timing for polymer floods is when the upper limit of water saturation is less than $S_{\mathrm{wu}}$. Before the fractional flow of water reaches the maximum value, the injection polymer solution can effectively control the increase of fractional water flow.

(3) The injection timing for polymer floods is when the lower limit of water saturation is greater than $S_{\mathrm{wL}}$. A certain amount of water injected before polymer flooding may effectively connect the flow channels in heavy oil reservoirs, cut the polymer cost and ensure the displacement efficiency of polymer flooding.

(4) Influenced by the service life of offshore platforms in Bohai heavy oil reservoirs, the injection timing should be selected at $S_{\mathrm{wL}}$. When the oil viscosity is $123 \mathrm{mPa} \mathrm{s}$, the optimum injection timing for polymer floods should be $10 \%$ of the fractional flow of water; and when the oil viscosity is $70 \mathrm{mPa} \mathrm{s}$, the optimum injection timing for polymer floods should be $25 \%$ of the fractional flow of water. Meanwhile, for polymer solutions with different mobility control capabilities, the optimum injection timing for polymer flooding should be varied as well.

Acknowledgments This paper was supported by Open Fund (CRI2012RCPS0152CN) of State Key Laboratory of Offshore Oil Exploitation and the National Science and Technology Major Project (2011ZX05024-004-01).

Open Access This article is distributed under the terms of the Creative Commons Attribution License which permits any use, distribution, and reproduction in any medium, provided the original author(s) and the source are credited.

\section{References}

Abu-shiekah IM, Nieuwenhuijs RA, Ross RW, et al. Developing a layered heterogeneous Precambrian reservoir by polymer flooding. SPE EOR conference at oil and gas West Asia, 16-18 Apr 2012, Muscat, Oman. (SPE 154465).

Aktas F, Clemens T, Castanier LM, et al. Viscous oil displacement with aqueous associative polymers. SPE symposium on improved oil recovery, 20-23 Apr 2008, Tulsa, Oklahoma, USA. (SPE 113264-MS). 
Alzayer A, Sohrabi M. Numerical simulation of improved heavy oil recovery by low-salinity water injection and polymer flooding. SPE Saudi Arabia section technical symposium and exhibition, 19-22 May 2013, Khobar, Saudi Arabia. (SPE 165287).

Asghari K, Nakutnyy P. Experimental results of polymer flooding of heavy oil reservoirs. Canadian international petroleum conference, 17-19 Jun 2008, Calgary, Alberta. (PETSOC-2008-189).

Bakhitov GG, Ogandzhanyants VG, Polishchuk AM. Experimental investigation into the influence of polymer additives in water on the relative permeabilities of porous media. Fluid Dyn. 1980;15(4):611-5.

Chang HG. Advances of polymer flood in heavy oil recovery. SPE heavy oil conference and exhibition, 12-14 Dec 2011, Kuwait City, Kuwait. (SPE 150384).

Crotti MA, Rosbaco JA. Relative permeability curves: the influence of flow direction and heterogeneities. SPE improved oil recovery symposium held in Tulsa, Oklahoma, 19-22 Apr 1988. (SPE 39657).

Delamaide E, Zaitoun A, Renard G, et al. Pelican lake field: first successful application of polymer flooding in a heavy oil reservoir. SPE enhanced oil recovery conference, 2-4 Jul 2013, Kuala Lumpur, Malaysia. (SPE 165234).

Delgado DE, Vittoratos E, Kovscek AR. Optimal voidage replacement ratio for viscous and heavy oil water floods. SPE western regional \& AAPG pacific section meeting 2013 joint technical conference, 19-25 Apr 2013, Monterey, California, USA. (SPE 165349).

Dou HE, Chen CC, Chang YW, et al. A new method of calculating water invasion for heavy oil reservoir by steam injection. Production and operations symposium, 31 Mar-3 Apr 2007, Oklahoma City, Oklahoma, USA. (SPE 106233).

Hu FZ. Polymer flooding production engineering. Beijing: Petroleum Industry Press; 2004. pp. 127-30.

Jiang RZ, Liu XT, Zhao W, et al. Study of a quantitative method for mobility design in polymer flooding. Pet Geol Recover Effic. 2010;17(5):39-41 (in Chinese).

Jiang WD, Lu GX, Ren YB. Study of oil and water relative permeability and water flooding efficiency in heavy oil reservoirs. Pet Geol Oilfield Dev Daqing. 2008;27(5):50-3 (in Chinese).

Kang XD, Zhang J, Sun FJ et al. A review of polymer EOR on offshore heavy oil field in Bohai Bay, China. SPE enhanced oil recovery conference, 19-21 Jul 2011, Kuala Lumpur, Malaysia (SPE 144932).

Kang XD, Zhang J. Offshore heavy oil polymer flooding test in JZW area. SPE heavy oil conference, 11-13 Jun, 2013, Calgary, Alberta, Canada. (SPE 165473).

Kumar M, Hoang V, Satik C, et al. High mobility ratio water flood performance prediction: challenges and new insights. SPE international improved oil recovery conference in Asia Pacific, 5-6 Dec 2005, Kuala Lumpur, Malaysia. (SPE 97671).

Lee KS. Effects of polymer adsorption on the oil recovery during polymer flooding processes. Pet Sci Technol. 2010;4(28):351-9.

Levitt D, Jouenne S, Igor B, et al. Polymer flooding of heavy oil under adverse mobility conditions. SPE enhanced oil recovery conference, 02-04 Jul, 2013, Kuala Lumpur, Malaysia. (SPE 165267).

Liu C, Liao XW, Zhang YL. Field application of polymer microspheres flooding: a pilot test in offshore heavy oil reservoir. SPE Annual Technical Conference and Exhibition, 8-10 Oct 2012, San Antonio, Texas, USA. (SPE 158293).

Ma SY. The pragmatic engineering method of polymer flood. Beijing: Petroleum Industry Press; 1995. pp. 42-4 (in Chinese).
Mahani H, Sorop TG, van den Hoek PJ, et al. Injection fall-off analysis of polymer flooding EOR. SPE reservoir characterisation and simulation conference and exhibition, 9-11 Oct 2011, Abu Dhabi, UAE. (SPE 145125).

Mogbo OC. Polymer flood simulation in a heavy oil field: offshore Niger-delta experience. SPE enhanced oil recovery conference, 19-21 Jul 2011, Kuala Lumpur, Malaysia. (SPE 145027).

Morelato P, Rodrigues L, Romero OJ. Effect of polymer injection on the mobility ratio and oil recovery. SPE heavy oil conference and exhibition, 12-14 Dec 2011, Kuwait City, Kuwait. (SPE 148875).

Rivas C, Gathier F. C-EOR projects-offshore challenges. The twentythird international offshore and polar engineering conference, 30 June-5 Jul, 2013, Anchorage, Alaska. (ISOPE-I-13-188).

Romero-Zeron LB, Li L, Ongsurakul S, et al. Visualization of waterflooding through unconsolidated porous media using magnetic resonance imaging. Pet Sci Technol. 2009;17(27): 1993-2009.

Shi JP, Li FQ, Cao WZ. Measurement of relative permeability curve of polymer flooding with non-steady state method. Daqing Pet Geol Dev. 2001;20(5):53-5 (in Chinese).

Shi LT, Chen L, Ye ZB, et al. Effect of polymer solution structure on displacement efficiency. Pet Sci. 2012;9(2):230-5.

Shi LT, Ye ZB, Zhang Z, et al. Necessity and feasibility of improving the residual resistance factor of polymer flooding in heavy oil reservoirs. Pet Sci. 2010;7(02):251-6.

Shi LT, Li C, Zhu SS. Study on properties of branched hydrophobically modified polyacrylamide for polymer flooding. J Chem. 2013;2013:1-5 Article ID 675826.

Torabi F, Zarivnyy O, Mosavat N. Developing new Corey-based water/oil relative permeability correlations for heavy oil systems. 2013 SPE Heavy Oil Conference, 11-13 Jun 2013, Calgary, Alberta, Canada. (SPE 165445).

Ye ZB, He EQ, Xie SY. The mechanism study of disproportionate permeability reduction by hydrophobically associating watersoluble polymer gel. J Petrol Sci Eng. 2010;72(1-2):64-6.

Zhang FJ, Jiang W, Sun FJ, et al. Key technology research and field tests of offshore viscous polymer flooding. Eng Sci. 2011a;13(5):28-33 (in Chinese).

Zhang JP, Sun FJ, An GR. Study of an incremental law of water cut and decline law in a water drive oilfield. Pet Geol Recover Effic. 2011b;18(6):82-5 (in Chinese).

Zhang XS, Sun FJ, Feng GZ, et al. Research into the factors influencing polymer flooding and field testing in Bohai heavy oil fields. China Offshore Oil Gas. 2007;19(01):30-4 (in Chinese).

Zhang XS, Wang HJ, Tang EG, et al. Research into reservoir potentials and polymer flooding feasibility for EOR technology in the Bohai offshore oilfield. Pet Geol Recover Effic. 2009;16(05):56-9 (in Chinese).

Zhang XS, Tang EG, Xie XG, et al. Study of the characteristics and development patterns of early polymer flooding in offshore oilfields. J Oil Gas Technol. 2013;35(07):123-6 (in Chinese).

Zhou FJ, Zhang LF, Wang HJ, et al. Experimental study into relative permeability curves of polymer flooding. Pet Geol Eng. 2010;24(6):117-9 (in Chinese).

Zhou SW. Exploration and practice of offshore oilfield effective development technology. Eng Sci. 2009;11(10):55-9 (in Chinese). 